\title{
When Should Private Label Brands Endorse Ethical Attributes?
}

Onur Bodur, Maryam Tofighi, and Bianca Grohmann

To cite this article: Bodur, Onur, Maryam Tofighi, and Bianca Grohmann (2016), "When Should Private Label Brands Endorse Ethical Attributes?" Journal of Retailing, 92, 204-217. doi:

10.1016/j.jretai.2015.11.001

To link to this article: $\underline{\text { https://doi.org/10.1016/j.jretai.2015.11.001 }}$ 
When Should Private Label Brands Endorse Ethical Attributes?

\begin{abstract}
Ethical attributes (i.e., product attributes that reflect social and environmental issues) do not always increase product evaluations and choice. This article examines whether ethical attributes differentially affect evaluations of retailers' private label brands (PLBs) and manufacturers' national brands (NBs). Two experiments show that ethical attributes enhance consumer evaluations of PLBs (but not NBs) in the presence of extrinsic cues signalling high quality (i.e., high price). In the context of extrinsic cues signalling low quality, (i.e., low price), an ethical attribute hurts PLB (but not NB) evaluations. This effect is mediated by consumers' product quality perceptions. A third experiment replicates these effects of ethical attribute presence on PLB evaluations in the context of retailer reputation serving as an extrinsic cue, and shows a moderating effect of consumers' resource synergy beliefs. Overall, these results suggest that PLBs benefit from offering ethical attributes in the context of higher-priced PLBs or higher retailer reputation.
\end{abstract}

Keywords: private label brand; national brand; ethical attributes; corporate social responsibility (CSR); resource synergy beliefs. 


\section{Introduction}

Ethical attributes are product attributes that have positive implications for environmental protection, human rights, animal welfare, and social issues such as disease prevention and the fight against poverty (Gupta \& Sen, 2013; Irwin \& Naylor, 2009; Luchs, Naylor, Irwin, \& Raghunathan, 2010). Ethical attributes can be integrated into the product (e.g., in terms of environmentally friendly or vegan product ingredients) or augment the product (e.g., causemarketing initiatives in the form of purchase-contingent contributions to a cause). Products with ethical attributes are of increasing importance to consumers and marketers. For instance, a survey of more than 28,000 online consumers from 56 countries revealed that $66 \%$ of consumers prefer to buy products and services from companies that give back to society, and 59\% are willing to invest in these companies (Nielsen, 2012). As a result, the market share of consumer product brands offering ethical attributes is growing rapidly (Nielsen, 2008). At the same time, there is a global rise in the market share of retailer-owned private label brands (PLBs). PLBsalso called store brands (AMA, 2014) — refer to consumer products that carry the retailer's name (e.g., Walgreens, CVS) or a brand name created by the retailer (e.g., Costco's Kirkland or Walmart's Great Value and Our Finest brands) for exclusive distribution in its stores (PLMA, 2014). PLBs are thus consumer products "branded by organizations whose primary economic commitment is distribution rather than production" (Richardson, Dick, \& Jain, 1994; p. 28). In the U.S., private label brands represent 17 percent of total sales and PLB sales are growing by about 13 percent annually (Nielsen, 2011). In Europe, the market share of private label brands exceeds $40 \%$ in many countries, such as the UK, Germany, Belgium, and Portugal (PLMA, 2013). The growth of PLBs is typically at the expense of manufacturer's national brands (NBs). NBs are brands of consumer products that are owned and advertised by manufacturers and 
marketed nationally or internationally (AMA, 2014; e.g., Tylenol, Lay's, Oasis). In a recent survey (Nielsen, 2013) ${ }^{1}, 46 \%$ of North American respondents declared that they would purchase more PLBs when food prices rise, whereas only 7\% would buy NBs. Among European respondents, $35 \%(8 \%)$ stated that they would buy more PLBs (NBs) as prices rise.

Against this backdrop of growing importance of ethical attributes and rising PLB market share, both NBs and PLBs increasingly offer products with ethical attributes. To shed light on the role of ethical attributes in increasing PLB preferences and to contribute to the literature on the effect of ethical product attributes on consumer responses (Brown \& Dacin, 1997; Irwin \& Naylor, 2009; Lin \& Chang, 2012; Luchs et al., 2010; Bodur, Gao, \& Grohmann, 2014), the current research examines whether the inclusion of ethical attributes benefits PLBs and NBs differently, and investigates the influence of price level, retailer reputation, and resource synergy beliefs in consumers' responses to PLBs offering ethical attributes. This article proceeds with a discussion of the conceptual framework underlying the effects of ethical attributes on PLB evaluations, and reports three experiments to test these effects. Experiment 1 shows that PLB price level (high vs. low price) moderates ethical attribute effects on PLBs, and identifies consumers' product quality perceptions as the underlying process. Experiment 2 replicates these results and shows asymmetric effects of ethical attribute presence and price level on PLBs and NBs. Experiment 3 extends the findings to ethical attributes offered by PLBs associated with low or high retailer reputation and finds a moderating effect of consumers' resource synergy beliefs. The article concludes with a discussion of implications and future research directions.

\section{Conceptual Background}

\section{Ethical Attribute Effects}


Firms increasingly engage in different types of social responsibility activities in the domains of consumer, employee, or environmental welfare (e.g., donations to philanthropic causes or commitment to diversity in hiring). Along with corporate philanthropy and ethical business practices, product-related social responsibility activities are an important component of firm's corporation social responsibility initiatives (Peloza \& Shang, 2011). Product-related social responsibility activities (hereinafter more concisely referred to as "ethical attributes") encompass product attributes that address social, environmental, or animal welfare concerns (Gupta \& Sen, 2013; Irwin \& Naylor, 2009; e.g., products that are child-labor free, environmentally friendly, or involve ingredients that are sustainable, non-toxic, not tested on animals) as well as cause-related marketing (i.e., support of a social or environmental cause that is linked to product sales; Varadarajan \& Menon, 1988). Although the presence of ethical attributes is often associated with more favorable product evaluations (Brown \& Dacin, 1997), increased product purchase likelihood (Auger, Devinney, Louviere, \& Burke, 2008), increased willingness to pay for the product (Trudel \& Cotte, 2009) and product choice (Barone, Miyazaki, \& Taylor, 2000; Gupta \& Sen, 2013), the impact of ethical product attributes on consumers' product evaluations is not always positive. Expected product category benefits, for example, moderate the influence of ethical attributes on product evaluations: Consumers favor ethical attributes to a greater extent in product categories in which gentleness serves as a core benefit (e.g., baby shampoo), but respond negatively to the presence of ethical attributes in product categories in which strength is an important product attribute (e.g., car shampoos; Luchs et al., 2010). The presence of ethical attributes also impacts consumers' judgment of product effectiveness negatively, and increases product consumption to compensate for perceived lack of effectiveness (e.g., for hand sanitizers; Lin \& Chang, 2012). Consumers show less preference for products with ethical attributes if the 
ethical attributes are incongruent with product category benefits — such as utilitarian ethical attributes (e.g., locally sourced ingredients) in symbolic product categories, and symbolic ethical attributes (e.g., cause-related marketing) in utilitarian product categories - compared to products for which ethical attribute and product category benefits are congruent (Bodur et al., 2014). In addition, the value consumers attach to ethical attributes also depends on contextual and individual difference factors: Ethical attributes are valued more when consumers form a consideration set by using an exclusion task rather than an inclusion task (Irwin \& Naylor, 2009). Similarly, the activation of consumers' self-accountability increases their preference for products with ethical attributes (Peloza, White, \& Shang, 2013). Finally, the weight consumers attach to ethical attributes and subsequent consumer preference for products featuring ethical attributes depends on consumers' resource synergy beliefs (i.e., the extent to which consumers believe that social responsibility activities enhance or detract from a firm's ability to provide high quality products or services) and the time frame associated with the decision (Gupta \& Sen, 2013).

\section{Ethical Attributes and Brand Evaluations}

The relation between the presence of ethical attributes and consumers' evaluations of product brands offering such attributes is an emergent topic. Research involving national brands in multiple product categories found a positive impact of social responsibility activities on consumers' brand responses: Perceptions of greater brand-level social responsibility resulted in stronger consumer-brand identification, more positive brand attitudes, purchase intentions, and consumer-based brand equity (Grohmann \& Bodur, in press). In an examination of national brands, the brand most strongly associated with social responsibility positioning (i.e., Stonyfield Farm yogurt) benefited from more favorable beliefs regarding the brand's social responsibility, leading to greater consumer-brand identification, and greater brand loyalty and advocacy 
behaviors, compared to competitor brands positioned on product performance (i.e., Dannon) or merely engaging in social responsibility activities without integrating them into the brand's core positioning (i.e., Yoplait's breast cancer campaign; Du, Bhattacharya, \& Sen, 2007). Despite the observed relational advantages (i.e., loyalty and advocacy) arising from the brand's social responsibility positioning, sales did not differ across national brands (Du et al., 2007).

Research on the effects of an embedded premium (EP; i.e., cause-related sales promotions in which a fixed amount or percentage of the price consumers pay for a product is donated to a cause) offered by a national brand carrying the corporate name shows that positive brand associations arising from exposure to the embedded premium do not only benefit the focal product, but carry over to a corporate brand's products in other categories, even if no embedded premium is offered in these categories (Henderson \& Arora, 2010). Exposure to embedded premiums offered by the brand in multiple categories did not strengthen this carry-over effect (Henderson \& Arora, 2010). In the context of a house-of-brands strategy (i.e., a corporation's brand portfolio consists of multiple brands competing in different categories; Rao, Agarwal, \& Dalhoff, 2004), the effectiveness of embedded premiums offered by national brands was inversely related to brand strength in the category, such that brands benefited more from embedded premiums when consumer preferences for brands competing within the category were relatively similar (Henderson \& Arora, 2010). In examining the effectiveness of embedded premiums, prior research also found positive embedded premium effects on brand attitude, purchase likelihood, and choice share for both known (i.e., NBs) and unknown (i.e., fictitious) brands (Arora \& Henderson, 2007). Importantly, the unknown brand benefited from offering an embedded premium to a greater extent in terms of percentage gains and effect sizes (Arora \& Henderson, 2007). This asymmetry has been linked to greater accessibility of the embedded 
premium as a cue in consumers' evaluation of an unknown brand and a greater potential for positive affect transfer from the embedded premium to the unknown (vs. known) brand (Arora \& Henderson, 2007). Overall, research on ethical attribute effects on consumer responses to NBs suggests that they often entail positive consequences, but depend on the evaluation and competitive context (Arora \& Henderson, 2007; Du et al., 2007; Henderson \& Arora, 2010) and the type of outcome considered (Du et al., 2007).

To shed more light on brand-level effects of ethical attributes, the current article investigates to what extent ethical attributes benefit retailers' PLBs. It also examines the possibility that consumers respond differently to an ethical attribute offered by PLBs and NBs, investigates the process underlying ethical attribute effects on PLBs, and explores potential moderators. This research seeks to contribute to knowledge regarding the effectiveness of ethical attributes across branding contexts, and to provide guidelines for retail managers who wish to make an informed decision regarding the allocation of resources to the provision of ethical attributes by their PLBs.

\section{Ethical Attribute Effects and PLB Evaluations}

In the absence of full information regarding a product's experiential attributes or product performance (i.e. intrinsic cues), consumer evaluations are based on heuristics (i.e., extrinsic cues) such as brand name, price, and retailer reputation (Dodds, Monroe, \& Grewal, 1991; Grewal, Krishnan, Baker, \& Borin, 1998; Rao \& Monroe, 1989). Brand name (e.g., NB versus PLB) has been identified as the most important cue in consumers' inference processes (Dodds et al., 1991; Rao \& Monroe, 1989) and in shaping consumer preferences (Richardson et al., 1994). The considerable marketing investment into NBs (e.g., extensive advertising support, sales promotion efforts to encourage trial and direct experience with the brand, innovation, packaging; 
Steenkamp, Van Heerde, \& Geyskens, 2010) results in strongly established NB quality perceptions (Milgrom \& Roberts, 1986) and strong consumer-based brand equity perceptions that go beyond high quality inferences (e.g., brand image; Sethuraman, 2003). Relatedly, NB product quality perceptions and willingness to pay for NBs exceed those of PLBs, even if the brands use identical ingredients (Richardson et al., 1994; Sethuraman, 2003). PLBs do not benefit from marketing communications support to the same extent as NBs (Steenkamp et al., 2010) and this may lead to consumer perceptions of PLB quality and non-quality related equity aspect (e.g., brand image) that are less positive compared to NBs (Richardson et al., 1994; Sethuraman, 2003). More recently, however, retail branding has moved from offering inexpensive generic alternatives to NBs to offering distinct PLBs positioned as "more value for money" as well as multi-tiered PLB strategies (Burt, 2000; Steiner, 2004), including economy (low-price/low-quality), standard (mid-price/mid-quality), and premium (high-price equal or close to the price of a NB/top-quality) PLBs (Geyskens, Gielens, \& Gijsbrechts, 2010). Although price serves as an extrinsic cue that strongly affects consumer inferences regarding quality (i.e., price-quality association; Kardes, Cronley, Kellaris, \& Posavac, 2004; Monroe \& Krishnan, 1985; Rao \& Monroe, 1988) and product performance (Shiv, Carmon, \& Ariely, 2005), it is a particularly diagnostic extrinsic cue in a multi-tiered PLB strategy context in which higherpriced PLBs are associated with higher quality levels that are comparable to NBs (Burt, 2000).

We propose that — because consumers draw on extrinsic cues when evaluating PLBsconsumers evaluate ethical attributes provided by a PLB in light of extrinsic cues associated with the brand. As a result, positive responses to ethical attribute presence are more likely to arise for PLBs that carry a relatively higher price (e.g., as a high-priced, premium-positioned PLB in a multi-tier PLB portfolio strategy). When consumers perceive a brand to be of higher quality 
based on extrinsic cues (e.g., high price), they may consider the presence of an ethical attribute as an additional functional (e.g., organic ingredients contribute to product's healthfulness) or symbolic benefit (e.g., cause-marketing constitutes a contribution to social or environmental welfare) and evaluate the PLB offering an ethical attribute more favorably. We therefore predict that ethical attribute presence enhances consumer evaluations of high-priced (vs. low-priced) PLBs. When it comes to the evaluation of low-priced PLBs, the benefits associated with ethical attributes may not contribute to the brand's perceived economy (i.e., low price/low quality) positioning, nor compensate for the lower quality levels associated with it (for a similar argument in the corporate social responsibility literature, see Berens, van Riel, \& van Rekom, 2007). An ethical attribute introduced by a low-priced PLB may therefore not positively influence brand evaluations, but have detrimental effects, because the ethical attribute is not in line with the PLB's economy positioning and the PLB could conceivably offer the product at a lower price if it did not incur the costs associated with offering the ethical attribute. We therefore expect that an ethical attribute offered by a low-priced PLB negatively affects brand evaluations.

This pattern of consumer responses to ethical attributes associated with a PLB likely extends to contexts where retailer reputation serves as an extrinsic cue in consumers' evaluation of the PLB. Retailer reputation reflects a retailers' commitment to quality (Dawar \& Parker, 1994; Dodds et al., 1991) in that retailers with a high reputation are motivated to maintain it by continuously offering products and brands of high quality (Purohit \& Srivastava, 2001). Brands carried by a highly reputed retailer may thus benefit from the positive quality associated with the retailer. Based on this discussion of the effect of extrinsic cues (i.e., price, retail reputation) on consumers' evaluation of PLBs offering ethical attributes, we hypothesize:

H1: The presence of an ethical attribute and extrinsic cues interact in influencing PLB 
evaluations, such that the presence (vs. absence) of an ethical attribute enhances evaluations of a PLB in the context of extrinsic cues signaling high quality (i.e., higher price or retailer reputation), whereas the presence (vs. absence) of an ethical attribute decreases evaluations of a PLB in the context of extrinsic cues signaling low quality (i.e., lower price or retailer reputation).

While this hypothesis suggests that the evaluations of PLBs offering ethical attributes are influenced by extrinsic cues (i.e., price, retailer reputation) in the evaluation context, we do not expect that these cues affect consumers' evaluation of NBs offering ethical attributes. Given the weight a NB name carries in consumers' quality and product performance perceptions (Dodds et al., 1991; Rao \& Monroe, 1989), consumers' NB evaluations should not be as susceptible to additional extrinsic cues (e.g., price, retailer reputation) as their PLB evaluations might be.

\section{The Mediating Role of Quality Perceptions}

The preceding discussion suggests that the extent to which consumers believe that the presence of an ethical attribute might influence overall quality by offering additional benefits may play a critical role in consumers' evaluations of PLBs that offer ethical attributes. We therefore expect that perceived quality mediates the ethical attribute $\times$ extrinsic cue interaction on consumers' PLB evaluations in the following manner: When a PLB offers an ethical attribute in the context of an extrinsic cue signaling higher quality (i.e., higher price or retailer reputation), consumers likely perceive that the ethical attribute positively relates to overall product quality, and subsequently evaluate the PLB more favorably. When a PLB offers an ethical attribute in the context of an extrinsic cue signaling lower quality (i.e., lower price or retailer reputation), the brand signals economy positioning (Geyskens et al. 2010), and consumers may not consider that the ethical attribute contributes to the expected brand benefits (i.e., offering lower quality but at a 
more affordable price) and the overall quality of the product offering. This indicates that consumers' quality perceptions mediate the interactive effect of ethical attribute presence and extrinsic cues on consumers' PLB evaluations for extrinsic cues signaling high quality.

H2: Perceived quality mediates the interaction effect of ethical attribute and extrinsic quality cues on PLB evaluations, such that the presence of ethical attribute offered by a PLB in a context of extrinsic quality cues signaling high quality (i.e., higher price or retailer reputation) enhances perceived quality and, in turn, enhances brand evaluations.

The presence of ethical attribute offered by a PLB in a context of extrinsic quality cues signaling low quality (i.e., lower price or retailer reputation) should not influence perceived quality and subsequent brand evaluations.

\section{The Moderating Role of Resource Synergy Beliefs}

Consumers' reactions to the use of ethical attributes by NBs and PLBs may also be influenced by resource synergy beliefs — consumer beliefs regarding the relationship between the resources invested in and the value added by social responsibility activities (Gupta \& Sen, 2013). Consumers with positive resource synergy beliefs associate social responsibility investments with increases in expertise, innovativeness, and capabilities to provide better products (Gupta \& Sen, 2013). Consumers who hold negative resource synergy beliefs, on the other hand, consider that an engagement in social responsibility activities is at the expense of product quality or innovativeness (Gupta \& Sen, 2013). In the context of PLBs offering products with ethical attributes, consumers with positive resource synergy beliefs likely perceive that a brand's investment in ethical attributes allows the brand to offer incremental functional or symbolic value. As a result, evaluations of PLBs offering ethical attributes should increase. For consumers 
with negative resource synergy beliefs, the implied trade-off between the PLB's investments in ethical attributes and product quality is likely to be most salient when the inferred quality of the product is initially low (e.g., based on an extrinsic cue suggesting low quality). Extrinsic cues suggesting higher quality, on the other hand, may reassure consumers with negative resource synergy beliefs that the ethical attribute does not come at the cost of product performance. As a result, for consumers with negative resource synergy beliefs, the presence of an ethical attribute should harm PLB evaluations in the presence of an extrinsic cue signalling low quality, but not in the presence of an extrinsic cue signalling high quality. In sum, we expect that-for consumers with negative resource synergy beliefs, ethical attribute presence in the context of an extrinsic cue signalling low quality decreases PLB evaluations. For consumers with negative resource synergy beliefs exposed to an ethical attribute in the context of an extrinsic cue signalling high quality, on the other hand, PLB evaluations should not decrease. Consumers with positive resource synergy beliefs should evaluate a PLB offering an ethical attribute positively, regardless of the quality level signaled by an extrinsic cue.

H3: Consumers' resource synergy beliefs moderate the interactive effect of ethical attribute presence and extrinsic cues, such that consumers with negative resource synergy beliefs evaluate a PLB offering an ethical attribute (vs. no ethical attribute) more negatively in the context of an extrinsic low quality cue, but not in the context of an extrinsic high quality cue. Consumers with positive resource synergy beliefs evaluate the PLB offering an ethical attribute (vs. no ethical attribute) more positively regardless of extrinsic cue context.

\section{Contributions of this Research}

This research examines to what extent the effectiveness of ethical attributes differs across 
extrinsic cue levels and brands (PLBs, NBs), to what extent this effect is driven by consumers' quality perceptions, and to what extent consumers' resource synergy beliefs moderate this effect. In focusing on these questions, the current article extends prior research in several ways: First, Arora and Henderson (2007) documented asymmetric effects embedded premiums, with unknown (fictitious) brands benefiting more from their inclusion compared to known (national) brands. This effect was explained in terms of a positive impact of a favorably valenced cue (i.e., the EP) on consumer responses to brands for which consumers had no prior associations. The current research adds to these findings by investigating to what extent brands with prior associations (i.e., PLBs) might benefit from offering ethical attributes and what role price and retailer reputation play in consumers' responses to ethical attributes offered by such brands. As such, in addition to extending the scope of ethical attributes examined (i.e., product-based ethical attributes rather than cause-marketing such as EP), the current research addresses the interactive effect of factors contributing to the success of ethical attributes that have not received much attention.

Second, this research also extends findings that show that quality is implicated in the relation between corporate social responsibility (CSR) and firm market value (Luo \& Bhattacharya, 2006). Previous research based on secondary data found that firms' product quality (as a dimension of corporate ability) influences the relation between CSR and firms' market value to some extent — such that high levels of product quality enhances the market value of CSR, whereas low levels of product quality do not have a detrimental influence on the relation between CSR and firms' market value — with this relation being partially mediated by consumer satisfaction (Luo \& Bhattacharya, 2006). Although this research included firms subsuming a wide range of product, service, and retail brands, brand-level implications of social responsibility 
activities were not considered. The current research examines the role of quality in the relation between ethical attribute presence and brand-related consumer responses from a different perspective in that it focuses on the causal relationship between ethical attribute presence, brand type (PLB vs. NB), and extrinsic quality cues (price, retailer reputation) on consumers' quality perceptions and subsequent responses to the brand in an experimental context involving product brands (both PLBs and NBs). Not only does the current article elucidate the differential role of extrinsic quality cues (moderators) and consumers' quality perceptions (mediator); it also examines the possibility that ethical attributes do not benefit all brands to the same extent and uniquely addresses the need to understand the potential benefits of offering ethical attributes in a competitive context involving PLBs and NBs.

Third, by considering the moderating role of consumers' resource synergy beliefs, the current article adds to current understanding of the extent to which individual difference variables influence the relationship between ethical attributes and consumers' brand evaluations. This research builds on Sen and Gupta's (2013) work by considering the moderating role of synergy beliefs on consumers' evaluations of ethical attributes provided by NBs and PLBs. Gupta and Sen (2013) manipulated consumers' resource synergy beliefs experimentally and examined its moderating role on the weighing of ethical attributes (Study 1) and preference (Study 2) of fictitious brands in the context of near versus distant decision time frames. Results suggested that consumers in the negative resource synergy belief condition weighted ethical attributes more heavily and preferred the product offering ethical attributes when considering the brands with regard to a distant (vs. close) timeframe, whereas consumers in the positive resource synergy condition were not sensitive to timeframe information. The current article adds to these findings in that it shows a moderating effect of resource synergy beliefs - treated here as a 
measured individual difference variable — on consumer responses to ethical attributes of existing brands. More specifically, the current research finds that PLB evaluations of consumers holding negative resource synergy beliefs depend on the nature of additional extrinsic quality cues (i.e., retailer reputation), whereas consumers holding positive resource synergy beliefs respond favorably to a PLB offering ethical attributes regardless of extrinsic cue information.

We now turn to the description of three experiments that empirically test the effect of ethical attributes on PLB evaluations in the presence of extrinsic cues signaling low versus high quality (H1; experiments 1, 2 and 3), the mediating role of perceived quality (H2; experiments 1 , 2, and 3), and the moderating effect of resource synergy beliefs (H3; experiment 3).

\section{Experiment 1: Effects of Ethical Attributes on PLBs at Different Price Levels}

This experiment examined whether an ethical attribute enhances PLB evaluations in the presence of an extrinsic cue signaling high quality (i.e., high price), but decreases PLB evaluations when there is an extrinsic cue signaling low quality (i.e., low price; H1). This study also investigated the mediating role of quality—operationalized here in terms of perceived quality impact of the ethical attribute-in this process (H2). The focus was on the presence (vs. absence) of a product-related ethical attribute (i.e., natural and locally grown ingredients) in the evaluation of potato chips - a product category with strong PLB presence.

\section{Pretest}

When consumers evaluate PLBs in a retail context, alternative NBs are usually available. To mimic a multi-brand evaluation context, we presented the focal PLB next to a NB alternative. To verify that perceived quality level was indeed lower for the PLB and to allow the experimental manipulation of quality perceptions due to an extrinsic cue (i.e., price level), we 
conducted a pretest. Twenty-two Canadian consumers (35\% female, between the ages of 19 and $\left.46, M_{\mathrm{age}}=29.18, S D=7.99\right)$ received $\$ .73$ to complete an online pretest via Mechanical Turk (MTurk) in which they rated the perceived quality of a set of NBs and PLBs ( $1=$ low quality, $7=$ high quality). Pretest results indicated that—in the potato chips product category-consumers considered Lay's $(M=5.47, S D=1.33)$ to be of higher quality than Our Finest offered by Walmart $(M=3.01, S D=1.07 ; F(1,21)=32.58, p<.01)$. In experiment 1 , Our Finest thus served as the PLB and Lay's as the NB.

\section{Method}

Experiment 1 used a 2 (ethical attribute: present vs. absent) $\times 2$ (PLB price: high vs. low) between-participants design with the within-participants presentation of the NB and PLB in all conditions. We counterbalanced PLB presentation (to the left or right of NB). A total of 81 Canadian consumers from a metropolitan area (46\% female, between the ages of 19 and 61, $M_{\text {age }}$ $=25.6, S D=9.56)$ completed a paper-and-pencil questionnaire for a chance to win a $\$ 100$ prize. Participants were randomly assigned to one of the experimental conditions. Due to missing responses, data from two participants was excluded from the analysis, resulting in a final sample of 79 participants.

Participants saw descriptions of a PLB (Our Finest) and an NB (Lay's) in the potato chips product category (illustrated in appendix A) that included or did not include an ethical product attribute for both the NB and the PLB. The PLB price manipulations comprised a high-price condition (PLB priced 5\% lower than the NB: \$3.59) or the low-price condition (PLB priced $40 \%$ lower than the NB). The NB carried a $\$ 3.79$ price tag in both conditions, reflecting the average price of Lay's chips at several local grocery stores at the time of data collection. Recent research suggests that grocery PLBs are priced around 25\% lower than NBs, with frequent price 
promotions of $20-30 \%$ (Volpe, 2011). We also checked potato chips prices at local supermarkets and observed price differences of up to $50 \%$ between NBs and PLBs. In light of these observations, the price difference of 5\% and 40\% between NB and PLB used in this experiment is realistic.

Participants evaluated both the PLB and the NB ("how would you rate [brand] potato chips?" 1 = extremely unappealing, 100 = extremely appealing; Bodur et al., 2014), completed a measure of perceived quality impact of the ethical attribute ("how much would the ethical attribute [i.e., made from natural and locally grown ingredients] improve the quality of product?" $1=$ does not improve quality at all, 7 = improves quality), and rated the importance of the ethical attribute ("how important is the following attribute to you: product is made from natural and locally grown ingredients", 1 = not important at all, 7 = very important).

\section{Results}

The presentation order of PLB (to the left or right of NB) did not have any significant main effect or interaction effects with any of the other factors (all $F_{\mathrm{s}}<1, p \mathrm{~s}>.30$ ). The subsequent analysis is thus based on pooled data. Given this study's focus on ethical attribute effects on PLB evaluations, we conducted an ANOVA with PLB evaluations as the dependent variable, and ethical attribute presence and price level as the independent variables. Results showed a significant interaction effect of ethical attribute presence and price level $(F(1,75)=$ 8.08, $p<.01$, partial $\eta^{2}=.09$ ), such that when PLB price was high, the ethical attribute marginally increased PLB evaluations $\left(M_{\text {NoEthical-HighP }}=38.94, S D=22.45 ; M_{\text {Ethical-HighP }}=54.17\right.$, $S D=25.51 ; F(1,75)=2.97, p<.10$, partial $\left.\eta^{2}=.04\right)$. When PLB price was low, however, the ethical attribute reduced PLB evaluations $\left(M_{\text {NoEthical-LowP }}=64.40, S D=29.52 ; M_{\text {Ethical-LowP }}=\right.$ 45.39, $S D=26.64 ; F(1,75)=5.39, p<.05$, partial $\left.\eta^{2}=.07\right)$. These results support hypothesis 1 . 
Figure 1 illustrates these findings. When NB evaluation served as a covariate, the interaction effect remained significant $(F(1,75)=7.56, p<.01)$ and the interaction pattern was consistent.

\section{INSERT FIGURE 1 HERE}

A follow-up regression analysis - with price, ethical attribute presence, and ethical attribute importance serving as predictors and NB evaluations as control variable-investigated whether ethical attribute importance influenced PLB evaluation. None of the effects involving ethical attribute importance reached significance (all $p \mathrm{~s}>.15$ ), eliminating individual differences in weighting of the ethical attribute as a potential explanation for the observed effects.

We further tested the conditional (on price) indirect effect of ethical attribute on PLB evaluations through perceived quality impact of the ethical attribute using PROCESS (Hayes, 2013; model 8, 5,000 bootstrap samples). We included ethical attribute presence as predictor (ethical attribute present $=1$, absent $=-1)$, price as the moderator $($ high price $=1$ and low price $=$ -1), PLB evaluation as the criterion, NB evaluation as the control, and perceived quality impact of the ethical attribute as the mediator. In support of $\mathrm{H} 2$, there was a significant indirect effect of the highest order interaction (total indirect effect $=1.54, \mathrm{SE}=1.09,95 \% \mathrm{CI}[.02,4.50]$ ). When PLB price was high, there was a marginally significant and positive indirect effect through perceived quality influence (conditional indirect effect $=1.36, \mathrm{SE}=1.29,90 \% \mathrm{CI}[.02,4.47]$ ). When PLB price was low, however, there was a marginally significant and negative indirect effect (conditional indirect effect $=-1.72, \mathrm{SE}=1.35,90 \% \mathrm{CI}[-4.76,-.15])$. There was a significant interaction effect on perceived quality impact of the ethical attribute $(B=4.43, t=$ $2.38, p<.05$ ), and perceived quality impact of the ethical attribute had a marginally significant impact on PLB evaluation $(B=3.60, t=1.90, p=.06)$. The direct effect of the ethical attribute was not significant after accounting for the indirect effect. 
In regard to NB evaluations, an ANOVA with NB evaluations serving as the dependent variable, and ethical attribute presence as the independent variable indicated that the ethical attribute did not improve NB evaluations $\left(M_{\text {NoEthical }}=85.19, S D=13.48 ; M_{\text {Ethical }}=84.58, S D=\right.$ $14.11 ; F(1,77)=.04, p>.80)$. Introducing PLB price as a factor and PLB evaluation as a covariate did not change these results. Planned contrasts in the repeated measures ANOVA did not show an ethical attribute effect on NB evaluations $(p s>.20)$. These results suggest that, although the ethical attribute influenced PLB evaluations in conjunction with price, it did not affect NB evaluations.

\section{Discussion}

Experiment 1 demonstrated that an ethical attribute enhanced evaluations of a PLB when a high price (within $5 \%$ of NB price) served as an extrinsic cue signaling higher quality. When PLB price was low ( $40 \%$ lower than NB price), however, the ethical attribute hurt PLB evaluations. Perceived quality impact of the ethical attribute mediated the conditional effect of the ethical attribute on PLB evaluations. The importance consumers attached to the ethical attribute did not explain these findings. Overall, experiment 1 suggests that price level is a boundary condition to the positive effect of ethical attribute on PLB evaluation. High PLB price serves as a quality indicator (Monroe \& Krishnan, 1985; Rao \& Monroe, 1988), such that addition of ethical attribute adds to the perceived quality, and increases PLB evaluations. When the PLB carries a low price, however, addition of an ethical attribute reduced PLB evaluation. These results suggest that ethical attributes benefit high-price PLBs, but harm low-price PLBs.

In this experiment, ethical attributes did not affect NB evaluation. This may be indicative of a ceiling effect: NB evaluations were generally higher than PLB evaluations ( 84.91 vs. 51.94). As experiment 1 focused on ethical attribute effects on PLB evaluation, NB price was not 
manipulated and the NB was always presented along the PLB. We address these issues and further investigate the impact of ethical attribute on NB evaluations in experiment 2.

\section{Experiment 2: Effect of Ethical Attributes on PLBs and NBs at Different Price Levels}

Experiment 1 revealed that a positive ethical attribute effect on PLB evaluations emerged when the PLB carried a high price, whereas the ethical attribute backfired when the PLB carried a low price. Experiment 2 replicates these findings in a different product category (orange juice) and examines the effect of ethical attribute and price on PLB and NB evaluations in a betweenparticipants design. To understand the underlying process, we further investigate mediation through overall quality perceptions of the brand, using a direct measure of perceived quality.

\section{Pretest}

This pretest identified a national brand and a private label brand that were similar in terms of brand familiarity, brand preference, CSR perceptions of the brand, fit of the ethical attribute with the brand, and quality perceptions, in order to ascertain that the proposed process based on quality perceptions can be attributed to the experimental factors. Twenty-six students (57\% female, between the ages of 18 and $\left.28, M_{\text {age }}=21.19, S D=2.55\right)$ from a large metropolitan university in Canada—recruited from the same population as the main study—participated in a PC-based pretest in the lab in exchange for course credit. Participants rated a set of NBs and PLBs in terms of brand familiarity $(1=$ low familiarity, $9=$ high familiarity $)$, brand quality $(1=$ low quality, 7 = high quality $)$, brand preference $(1=$ unfavorable, $7=$ very favorable $), \mathrm{CSR}$ perceptions of the brand ( $\alpha=.92$, four items, e.g., "to what extent do you agree that [brand] gives back to the communities in which it does business/is a socially responsible brand"; $1=$ strongly disagree, $7=$ strongly agree $)$, and brand-ethical attribute fit $(1=$ low fit, $7=$ high fit $)$. 
We selected Oasis as the NB and President's Choice as the PLB based on paired t-tests indicating that these brands did not differ in brand familiarity $\left(M_{\text {Oasis }}=8.35, S D=1.33, M_{P C}=\right.$ 8.12, $S D=1.18, p>.47)$, brand preference $\left(M_{\text {Oasis }}=5.20, S D=1.71, M_{P C}=5.24, S D=1.13, p>\right.$ $.91)$, CSR perceptions of the brand (Masis $\left.=4.41, S D=1.55, M_{P C}=4.34, S D=1.16, p>.79\right)$, brand-ethical attribute fit (Moasis $\left.=5.23, S D=1.56, M_{P C}=5.54, S D=1.24, p>.37\right)$, and quality $\left(M_{\text {Oasis }}=5.19, S D=1.65, M_{P C}=5.00, S D=1.41, p>.61\right)$. In a second pretest $(\mathrm{n}=49$, between the ages of 18 and 37, $M_{\text {age }}=22.1, S D=3.40,43 \%$ females — conducted as part of an unrelated study with participants from the same population —we measured perceived ethicality of a number of ethical attributes ("how ethical do you think the following attribute is? [ethical attribute description]", 1 = not at all ethical, 7 = very ethical). The attribute "made from naturally supplied ingredients/materials" was perceived to be ethical $(M=5.78, S D=1.45$; compared to scale mid-point $(4): t(48)=8.47, p<.01)$ and thus served as the focal ethical attribute in experiment 2.

\section{Method}

Experiment 2 used a 2 (ethical attribute: present vs. absent) $\times 2$ (brand type: PLB vs. NB) $\times 2$ (price: high vs. low) between-participants design. A total of 197 students ( $46 \%$ female, between the ages of 17 and $39, M_{\mathrm{age}}=21.5, S D=3.3$ ) participated in a PC-based study in exchange for course credit. Participants saw descriptions for a PLB (President's Choice) or NB (Oasis) in the orange juice category. The descriptions (illustrated in appendix A) either included (EA present) or did not include an ethical attribute (EA absent). The price manipulations were based on the regular prices for three leading brands observed at multiple outlets of three different retailers at the time of data collection. The average of these prices was used as the high price manipulation. The price presented in the low price condition was $40 \%$ below the regular price. 
This depth of promotion is consistent with the range of price promotion depths observed in NB/PLB prices in major supermarket chains (Volpe, 2011) and the depth of price promotions reported in earlier research (Tellis \& Zufryden, 1995). Given that the price manipulation was between-participants, low/high price levels were applied to both NB and PLB.

\section{Measures}

Brand appeal and brand attitude served as measures of brand evaluation. Brand appeal was measured on a 100-point scale ("how appealing is [brand] orange juice?" $1=$ extremely unappealing, 100= extremely appealing). The brand attitude measure consisted of three sevenpoint scales $(\alpha=.95$; "how would you evaluate [brand] orange juice?" $1=$ unfavorable/bad/ negative, 7 = favorable/good/positive). We obtained a measure of the overall quality of the brand ("how would you rate the overall quality of [brand] orange juice?" $1=$ low quality, $7=$ high quality). As a control variable, we also measured the relevance of the ethical attribute to the brand ("how relevant is offering products made from natural and locally supplied ingredients/materials to [brand]?" $1=$ not at all relevant, $7=$ very relevant .

\section{Results}

A MANOVA with brand appeal and attitude as the dependent variables revealed more favorable NB evaluations overall (i.e., main effect of brand: $F(2,188)=13.32, p<.01$, partial $\eta^{2}$ $=.12$ ). This effect was qualified by a three-way interaction of brand, ethical attribute, and price $\left(F(2,188)=4.53, p<.01\right.$, partial $\left.\eta^{2}=.05\right)$. At the univariate level, results were consistent, with minor differences across the two dependent measures: For brand attitude, there was a significant main effect of brand $\left(F(1,189)=25.85, p<.01\right.$, partial $\left.\eta^{2}=.12\right)$, a significant two-way interaction of ethical attribute and price $\left(F(1,189)=4.30, p<.05\right.$, partial $\left.\eta^{2}=.02\right)$, and a threeway interaction of brand, ethical attribute, and price $\left(F(1,189)=6.02, p<.01\right.$, partial $\left.\eta^{2}=.03\right)$. 
When the price was high, consumers evaluated the PLB more favorably when it offered an ethical attribute $\left(M_{\text {PLB-E-HiP }}=5.55, S D=.77\right)$ versus not $\left(M_{\text {PLB-NE-HiP }}=4.90, S D=1.61 ; F(1\right.$, $189)=5.04, p<.05$, partial $\left.\eta^{2}=.03\right)$. When the price was low, the inclusion of an ethical attribute backfired, such that the PLB without the ethical attribute was evaluated more favorably $\left(M_{\text {PLB-NE-lowP }}=5.58, S D=1.18\right)$ compared to the PLB with the ethical attribute $\left(M_{\text {PLB-E-LoP }}=\right.$ $4.81, S D=1.33 ; F(1,189)=5.01, p<.05$, partial $\left.\eta^{2}=.03\right)$. For the NB, brand attitude did not change with the introduction of the ethical attribute at low or high price level (all $F_{\mathrm{s}}<1, p \mathrm{~s}>$ .20). Figure 2 illustrates this interaction.

INSERT FIGURE 2 HERE

When brand appeal served as the dependent variable, there was a significant main effect of brand $\left(F(1,189)=17.29, p<.01\right.$, partial $\left.\eta^{2}=.08\right)$ and a significant three-way interaction $\left(F(1,189)=8.73, p<.01\right.$, partial $\left.\eta^{2}=.04\right)$ : When the price was high, consumers found the PLB more appealing when it had an ethical attribute $(M$ PLB-E-HiP $=67.50, S D=16.25)$ versus not $\left(M_{\text {PLB-NE-HiP }}=57.94, S D=23.96 ; F(1,189)=3.38, p=.07\right.$, partial $\left.\eta^{2}=.02\right)$. When the price was low, the PLB with the ethical attribute was perceived as less appealing $\left(M_{\text {PLB-E-LoP }}=59.86, S D=\right.$ 25.76) compared to the PLB without the ethical attribute $\left(M_{\mathrm{PLB}-\mathrm{NE}-\mathrm{LoP}}=72.95, S D=20.01 ; F(1\right.$, $189)=4.47, p<.05$, partial $\eta^{2}=.02$ ). For the NB, ethical attribute did not have an effect, regardless of whether the price was high or low (all $p \mathrm{~s}>.12$ ). The multivariate contrasts were marginally significant, but consistent: The high priced PLB was evaluated more favorably when it had an ethical attribute versus not $\left(F(2,188)=2.82, p=.06\right.$, partial $\left.\eta^{2}=.03\right)$, whereas the low priced PLB was evaluated less favorably when it had an ethical attribute versus not $(F(2,188)=$ $2.60, p=.08$, partial $\eta^{2}=.03$ ). For the NB, there were no significant differences at the multivariate level (all $F \mathrm{~s}<1.6, p \mathrm{~s}>.20$ ). Overall, univariate and multivariate interaction patterns 
support hypothesis 1 .

Mediating role of quality perceptions. We further tested the conditional (on price) indirect effect of ethical attribute on brand evaluation through perceived quality. PROCESS (Hayes, 2013; model 12, 5,000 bootstrap samples) — with ethical attribute presence as the predictor (ethical attribute $=1$ and control $=-1)$, price (high price $=-1$ and low price $=1)$ and brand (national brand $=1$, PLB $=-1$ ) as the moderators, brand appeal as the criterion, and perceived quality as the mediator-indicated that quality perceptions mediated the effect of the highest order (three-way) interaction on brand appeal (total indirect effect $=-1.88, \mathrm{SE}=.95,95 \%$ CI [$.03,-3.80])$. The conditional indirect effect was marginally significant for the PLB at high price (conditional indirect effect $=3.13, \mathrm{SE}=1.96,90 \% \mathrm{CI}[.06,6.56])$, suggesting that an ethical attribute, when introduced with a high price, improved quality perceptions and consequently, brand appeal. As expected, when the price was low, the indirect effect of the ethical attribute on PLB appeal was negative, but not significant (conditional indirect effect $=-4.18, \mathrm{SE}=2.53, p>$ .10). There was a significant three-way interaction effect on perceived quality $(B=-.16, S E=$ $.08, t=-2.01, p<.05,95 \% \mathrm{CI}[-.01, .33])$ and there was a significant positive impact of perceived quality on brand appeal $(B=11.47, S E=.94, t=12.20, p<.01,95 \%$ CI $[9.62,13.33])$.

The results were similar with regard to brand attitude: perceived quality mediated the effect of the highest order (three-way) interaction on brand attitude (total indirect effect $=-.14$, $\mathrm{SE}=.07,95 \% \mathrm{CI}:[-.01,-.28])$. When PLB price was high, the conditional indirect effect on PLB attitude was positive and marginally significant (conditional indirect effect $=.23, \mathrm{SE}=.14,90 \%$ CI $[.01, .47])$, suggesting that an ethical attribute coupled with a high price improved quality perceptions and subsequent PLB attitude. When the price was low, the indirect effect of the ethical attribute on PLB attitude was negative, but not significant (conditional indirect effect = - 
$.31, \mathrm{SE}=.19, p>.10)$. There was a significant three-way interaction effect on perceived quality $(B=-.16, S E=.08, t=-2.01, p<.05,95 \% \mathrm{CI}[-.01,-.33])$ and a significant positive impact of perceived quality on brand attitude $(B=.84, S E=.03, t=25.56, p<.01,95 \% \mathrm{CI}[.78, .91])$. The indirect effect of ethical attribute on NB appeal or attitude was not significant in the low and high price conditions. Overall, the mediation results with both dependent variables support hypothesis 2 .

Eliminating alternative explanations. An potential alternative explanation for the differential NB versus PLB evaluations is that the ethical attribute may be perceived as more relevant to one of the brands. An ANOVA with relevance of the ethical attribute to the brand as the dependent variable, brand, ethical attribute presence, and price as the independent variables revealed no significant difference between the brands $(p>.10)$ and none of the other main or interaction effects were significant. When we included ethical attribute relevance as a covariate in the analysis, there was a significant main effect of ethical attribute relevance on both brand appeal and brand attitude $\left(F_{\mathrm{s}}>19, p \mathrm{~s}<.01\right)$. However, the significance level and the effect size for the three-way interaction reported earlier improved for both brand appeal $\left(p=.002\right.$, partial $\eta^{2}$ $=.050)$ and brand attitude $\left(p=.012\right.$, partial $\left.\eta^{2}=.033\right)$. The interaction pattern did not change, ruling out differential relevance of ethical attribute to the brands as an alternative explanation.

Secondly, ethical attributes might be more effective in increasing choice likelihood for unknown brands, such that - if consumers have little knowledge about a given brand - the marginal impact of ethical attribute information on brand evaluations increase (Arora \& Henderson, 2007). This explanation cannot account for the current results, as this study employed real brands that were pretested and selected based on similar brand familiarity levels.

\section{Discussion}


Experiment 2 showed that the impact of an ethical attribute on brand evaluations depends on the brand type (PLB or NB) and the presence of an extrinsic quality cue (price level), and that quality perceptions mediate the effect of ethical attribute on PLB evaluations at high price levels. For PLBs, the ethical attribute increased brand evaluations only when the extrinsic cue (i.e., high price) signaled higher quality, but hurt evaluations when the extrinsic cue (i.e., lower price) signaled lower quality. This supports H1. Based on pretest results and additional analyses, brand familiarity, CSR perceptions of the brands, brand-ethical attribute fit, and relevance of the ethical attribute to the brand were eliminated as alternative explanations. Notably the ethical attribute did not improve NB evaluations at any price level, which is consistent with experiment 1 results. The absolute level and similarity of preference for NB and PLB determined in the pretest suggests that a ceiling effect in NB evaluations is not a likely explanation of NB related findings.

In experiments 1 and 2, price served as an extrinsic cue, but based on the literature, other extrinsic cues may affect consumers' brand evaluations. One such cue is reputation of the retailer offering the PLB. An investigation of this cue could lead to actionable implications regarding what type of retailer could benefit more from introducing ethical attributes as part of their PLB offering. Experiment 3 addresses this question.

\section{Experiment 3: Effects of Ethical Attributes on PLBs across Retailer Reputation Levels}

Experiments 1 and 2 showed a positive impact of the ethical attribute on PLB evaluation when high price served as a quality cue for PLB. In experiment 3, we use retailers' reputation regarding quality—hereinafter referred to as retailer reputation— to test whether the ethical attribute improves (weakens) brand evaluation of a PLB offered by a retailer associated with high (low) retail reputation. Based on previous literature (Lin \& Chang, 2012), we employed a 
different ethical attribute (i.e., environmentally friendly ingredients) for personal care and household cleaning products (i.e., hand soap and laundry detergent) in this study. This study also tested $\mathrm{H} 3$ regarding the moderating role of consumers' resource synergy beliefs.

\section{Pretest}

This pretest sought to identify retailers with differential quality reputations, but similar levels of familiarity and CSR perceptions. Twenty-four Canadian students ( $54 \%$ female, between the ages of 20 and $39, M_{\text {age }}=21.8, S D=3.9$ ) - recruited independently from the main study sample — received course credit to complete a PC-based pretest. Participants rated a set of retailers on measures relevant to potential confounding factors and the intended manipulation, such as perceived familiarity $(1=$ low familiarity, $7=$ high familiarity $)$, retailer's reputation $(1=$ low quality, $7=$ high quality, retailer's CSR perception $(\alpha=.79$, four items, e.g., "to what extent do you agree that [retailer] is a socially responsible brand?" $1=$ strongly disagree, $7=$ strongly agree), and retailer-ethical attribute fit ("if [retailer] were to introduce environmentally friendly products, how would you evaluate their fit with [retailer]?" $1=$ low fit, $7=$ high fit). Based on the pretest findings, we selected the (national) retailers IGA and Maxi for inclusion in experiment 3: The retailer IGA $\left(M_{I G A}=6.71, S D=3.41\right)$ was associated with a higher retailer reputation than $\operatorname{Maxi}\left(M_{M A X I}=5.38, S D=3.47 ; t(23)=6.22, p<.01\right)$, but the retailers did not differ in familiarity $(p>.61)$, retailer's CSR perceptions $(p>.58)$, or retailer-ethical attribute fit $(p>.10)$.

\section{Method}

Experiment 3 employed a 2 (ethical attribute: present vs. absent [control]) $\times 2$ (retailer reputation: high vs. low) $\times 2$ (product category: hand soap, laundry detergent) mixed design with ethical attribute and retailer reputation as between-participants factors and product category as within-participants factor. A total of 147 university students from a large Canadian metropolitan 
area ( $53 \%$ female, between the ages of 17 and $\left.32, M_{\text {age }}=21.2, S D=2.7\right)$ participated in this PCbased study in exchange for course credit.

Participants read the descriptions of a fictitious PLB (Labrada) introduced by a retailer with either high retail reputation (IGA) or low retail reputation (Maxi) in the hand soap and laundry detergent categories. The order of product category presentation was counterbalanced. The use of a fictitious PLB allowed us to use an identical PLB manipulation across the two retailers to preclude confounds. Because the introduction of multiple PLBs is a common practice among retailers (Geyskens et al., 2010), this manipulation has ecological validity. The descriptions (illustrated in appendix A) included an ethical attribute (EA present) or did not (EA absent). To ascertain external validity, the prices presented in this study were determined by obtaining the average regular price of three existing brands in each product category that were readily available at three different local retailers at the time of data collection.

\section{Measures}

In each product category, participants evaluated the PLB on a number of relevant measures, including PLB evaluation ("on a scale of 1-100, how appealing is Labrada [product] offered by [retailer]?"), overall quality of the brand ("how would you rate the overall quality of [brand] [product]?" 1 = low quality, 7 = high quality), and perceived quality impact of the ethical attribute ("how much would the following attribute influence the quality of [product]? [environmentally friendly ingredients]" $1=$ decreases quality, $7=$ increases quality). Note that different from experiment 1 , we revised the scale anchors to capture perceptions of quality decreases as well as increases. We measured individual-level resource-synergy beliefs, using a five-item scale based on Gupta and $\operatorname{Sen}(2013 ; \alpha=.94$; e.g., "socially responsible behavior by firms is often accompanied by inferior product offerings," $1=$ strongly disagree, $7=$ strongly 
agree). We also included other measures to assess potential confounding variables, including perceived ethicality of the focal attribute ("how ethical do you think the following attribute [environmentally friendly ingredients] is ..." $1=$ not at all ethical, $7=$ very ethical), relevance of the ethical attribute to the retailer ("how relevant is the following attribute to [retailer]? [environmentally friendly ingredients]", $1=$ not at all relevant, $7=$ very relevant), brand-self connection ( $\alpha=.93$, five items, based on Escalas \& Bettman, 2003; e.g., "[brand] reflects who I am," "I can identify with [brand]," "I consider [brand] to be me," 1 = strongly disagree, $7=$ strongly agree).

\section{Results}

The focal ethical attribute used in this study was perceived to be ethical $(M=6.21, S D=$ 1.13; comparison to scale mid-point $(4): t(145)=23.54, p<.01)$ and relevant to the retailers $(M$ $=5.20, S D=1.52$; comparison to scale mid-point $(4): t(146)=9.58, p<.01)$. There were no significant differences between the retail reputation conditions in terms of perceived ethicality of the environmentally friendly attribute $(F<.01, p>.90)$, the relevance of the ethical attribute to the retailer $(F<.50, p>.40)$, or brand-self connection $(F<.60, p>.40)$. An initial repeatedmeasures ANOVA with product category (within-participants factor), ethical attribute presence, retailer reputation, and product category presentation order as independent variables and PLB evaluation as the dependent variable revealed no significant interactions involving product category or presentation order (all $F \mathrm{~s}<.30, p \mathrm{~s}>.50$ ). We therefore pooled the data across presentation orders.

A repeated-measures ANOVA with ethical attribute presence and retailer reputation as between-participants factors, product category (hand soap and laundry detergent) as withinparticipants factor, and PLB evaluation as the dependent variable revealed a significant main 
effect of ethical attribute presence $\left(M_{E}=61.94, M_{N E}=55.84 ; F(1,143)=4.96, p<.05\right.$, partial $\eta^{2}$ $=.034)$, but no significant main effect for retailer reputation $(\mathrm{F}(1,143)=1.65, p>.20)$ or interactions involving product category (all $F \mathrm{~s}<1, p \mathrm{~s}>.70$ ). The main effect of ethical attribute presence was qualified by a significant two-way interaction involving retailer reputation $(F(1$, $143)=7.27, p<.01$, partial $\left.\eta^{2}=.048\right)$. Ethical attribute presence improved PLB evaluation when the PLB was offered by the high reputation retailer $\left(M_{I G A-N E}=53.90, S D=15.80 ; M_{I G A-E}=\right.$ 67.40, $S D=13.46 ; F(1,143)=11.42, p=.001$, partial $\left.\eta^{2}=.074\right)$, but did not influence PLB evaluations when it was offered by the low reputation retailer $\left(M_{M A X I-N E}=57.77, S D=16.62\right.$; $\left.M_{M A X I-E}=56.49, S D=19.45 ; F(1,143)=.12, p>.70\right)$. The interaction pattern was similar for both product categories and is illustrated in Figure 3. Ethical attribute presence improved PLB evaluation when the PLB was associated with a high reputation retailer for both laundry detergent $\left(M_{I G A-N E}=54.37, S D=20.19 ; M_{I G A-E}=67.35, S D=20.49 ; F(1,143)=6.16, p<.01\right.$, partial $\left.\eta^{2}=.041\right)$ and hand soap $\left(M_{I G A-N E}=53.43, S D=18.97 ; M_{I G A-E}=67.44, S D=17.31 ; F(1\right.$, $143)=8.53, p<.01$, partial $\eta^{2}=.056$ ). These results support hypothesis 1 . The significance of the interaction and the pattern of results did not change when we introduced ethical attribute relevance and brand-self-connection as covariates. ${ }^{2}$

INSERT FIGURE 3 HERE

Mediating role of quality perceptions. We further tested whether the conditional (on retailer reputation) effect of ethical attribute on PLB evaluations is mediated through perceived quality. PROCESS results (Hayes, 2013; model 8, 5,000 bootstrap samples), with ethical attribute presence as the predictor (ethical attribute present $=1$, absent $=-1$ ), retailer reputation as the moderator (low $=-1$, high $=1$ ), quality perception as the mediator, and PLB evaluations as the criterion, revealed a marginally significant indirect effect of the highest order interaction 
(total indirect effect estimate $=1.05, \mathrm{SE}=.67,90 \% \mathrm{CI}[.06,2.29])$. Consistent with predictions, this effect was driven by high retailer reputation serving as the extrinsic cue: At high retailer reputation, the ethical attribute significantly improved PLB evaluations through quality perceptions (conditional indirect effect $=2.64, \mathrm{SE}=.99,95 \% \mathrm{CI}[.86,4.75])$. When retailer reputation was low, the indirect effect was not significant (conditional indirect effect $=.55, \mathrm{SE}=$ $.87, p>.10)$

We also assessed the perceived quality impact of the ethical attribute, as a more specific measure of quality influence of the ethical attributes. Results of a PROCESS analysis (Hayes, 2013; model 8, 5,000 bootstrap samples), with quality impact of the ethical attribute as the mediator, ethical attribute presence as the predictor, retailer reputation as the moderator, and PLB evaluations as the criterion, revealed a significant indirect effect of the highest order interaction (total indirect effect estimate $=.38, \mathrm{SE}=.28,95 \% \mathrm{CI}[.01,1.16])$. When retailer reputation was high, the indirect effect of ethical attribute on PLB evaluations was significant (conditional indirect effect $=.57, \mathrm{SE}=.37,95 \% \mathrm{CI}[.06,1.58]$ ), but not when the retailer reputation was low (conditional indirect effect $=-.21, \mathrm{SE}=.33,95 \% \mathrm{CI}[-1.13, .26])$. Combined, these results suggest that when the retailer reputations is high, retailer name serves as a quality cue and strengthens the impact of ethical attributes in the evaluation of PLBs. Consistent process findings with both quality perception and quality impact measures support hypothesis 2 .

Moderating role of resource-synergy beliefs (RSB). We tested the moderating role of consumers' resource-synergy beliefs in the evaluation of ethical attributes. A regression analysis with ethical attribute, retailer reputation, and RSB (higher scores indicate negative RSB) as the predictors, and PLB evaluation as the criterion across both product categories revealed a marginally significant three-way interaction (PROCESS, model 3, 5,000 bootstrap samples, $B=$ 
$1.47, S E=.87, t=1.68, p<.10$ ) that supports hypothesis 3 . The interaction pattern (Figure 4) suggests that for participants with positive RSB (-1 SD), ethical attribute presence had a positive impact on PLB evaluations at both high $(B=6.70, S E=2.80, t=2.40, p<.05)$ and low retail reputation $(B=4.50, S E=2.70, t=1.67, p<.10)$. For participants with negative $\mathrm{RSB}(+1 \mathrm{SD})$, the ethical attribute had a positive impact on PLB evaluation when the PLB was offered by the high reputation retailer $(B=6.70, S E=3.16, t=2.12, p<.05)$, but backfired when the PLB was associated with the low reputation retailer $(B=-5.06, S E=2.51, t=-2.02, p<.05)$. The differential effect of ethical attribute on PLB evaluations at low and high levels of retailer reputation was significant for RSB scores above 3.09, based on Johnson-Neyman results.

\section{INSERT FIGURE 4 HERE}

\section{Discussion}

The results of this study show that an ethical attribute improves PLB evaluations-across two product categories - when offered by a retailer with high retail reputation, but not when offered by a retailer with low retail reputation. When retailer reputation is high, the retailer name serves as a quality cue, increasing the positive impact of the ethical attribute on perceived quality and, consequently, PLB evaluation. The mediation through quality perceptions and the quality influence of the ethical attribute provide consistent results and is in line with the mediation results of experiments 1 and 2. Importantly, for individuals with more negative resource-synergy beliefs, ethical attribute presence improves PLB evaluation when offered by a high reputation retailer, but hurts PLB evaluations when offered by a low reputation retailer (supporting H3). For individuals with positive resource-synergy beliefs, ethical attribute presence improves PLB evaluations, regardless of the retailer quality associations. Familiarity with the retailer, retail brand self-connection, CSR perceptions of the retailers, relevance of the ethical attribute to the 
brand, and fit of the ethical attribute with the retailer are ruled out as alternative explanations.

\section{Conclusion and Implications}

Although the inclusion of ethical product attributes frequently entails positive consequences in terms of brand evaluation and choice, its effects are not always favorable. Whereas prior research has identified benefit sought in a product category (Luchs et al., 2010), the congruity between product category benefit and ethical attribute benefit (Bodur et al., 2014), and brand concept (self-enhancement vs. self-transcendence; Torelli et al., 2012) as moderators of the influence of ethical attributes on consumer responses, the current research extends the investigation of moderators that affect consumers' evaluations of products with ethical attributes to brand type (i.e., PLB vs. NB), price level (i.e., high-priced vs. low-priced PLB), and retailer reputation (i.e., low vs. high retailer reputation).

The experiments presented herein used a variety of real national and private label brands (with the exception of the product brand used in experiment 3), different product categories, and different ethical attributes as stimuli, and support the view that adding an ethical attribute to a brand is not always beneficial. The effectiveness of an ethical attribute in enhancing consumers' brand evaluations is contingent upon the type of brand and the price level, such that NBs benefit from ethical attributes to a lesser extent than do PLBs. Moreover, the ethical attribute enhances evaluations of a private label brand only when it is high-priced or offered by a reputable retailer, and this effect is reversed when the PLB carries a low price. Particularly among consumers with negative resource synergy beliefs, PLB evaluations also decrease if an ethical attribute is offered in a context of lower levels of retail reputation. The positive (negative) effect of ethical attributes on consumer evaluations of high-priced (low-priced) PLB is mediated by perceived quality 
associated with the ethical attribute.

\section{Theoretical Implications}

In line with the consideration of both positive and negative effects of ethical attributes on consumers' product and brand evaluations that has emerged in recent literature (e.g., Luchs et al., 2010; Torelli et al., 2012), the current research finds that the ethical attribute-brand evaluation relation depends on factors such as brand type (NB, PLB), price-level, or retailer reputation. Product attributes and brand name play an important role in consumers' judgments of products. When a desirable product attribute — such as an ethical attribute that is associated with functional (e.g., sustainable ingredients) benefits for consumers - is included in the product offering, this addition may shift the focus from the brand name to itself, and reduces the effect of brand equity on quality judgments (Van Osselaer \& Alba, 2003); this effect seems to occur for the PLB to a much greater extent than the NB, however. The current research has theoretical implications for the brand equity literature in that it examines the effect of an ethical attribute on consumer judgments resulting from the difference in brand equity (NB vs. PLB). Experiment 1, in particular, suggests that when price-level — and inferred quality — of a PLB is close to a NB, the desirable ethical attribute shifts the focus from the NB to the PLB, and enhances PLB evaluations in a competitive brand presentation context. Results were similar when the PLB and NB were evaluated in isolation (experiment 2). Finally, the fact that a PLB associated with an extrinsic cue associated with higher quality benefited from the introduction of an ethical attribute extended beyond price cues to retail reputation, and resource synergy beliefs moderated this effect (experiment 3).

\section{Practical Implications}

This research has managerial implications regarding the likely success of the introduction 
of ethical attributes by PLBs versus NBs. The findings suggest that PLBs stand to gain more from the introduction of ethical attributes compared to NBs, particularly when they are highpriced or offered by a reputable retailer. The lift arising from ethical attributes offered by PLBs held across different ethical attributes (i.e., environmental friendliness, natural and locally sourced ingredients), which suggests that retailers have a wide range of choices regarding the ethical attributes they wish to pair with their PLBs. Retailers pursuing a two-tier or multi-tier PLB strategy that provides both high-quality/high price (top-tier quality) PLBs and lowquality/low-price (low-tier quality) PLBs to consumers (Geyskens et al., 2010; Steiner, 2004) and seeking to enhance evaluations of the PLBs might benefit from introducing ethical attributes for their top-tier, higher-priced PLBs. Importantly, for lower-priced PLBs, the introduction of an ethical attribute hurts brand evaluations and is thus not recommended. Similarly, retailers that operate retail store brands associated with differential retailer reputation (e.g., Loblaw's Maxi [low retail reputation] vs. Loblaws [high retail reputation] supermarket chains) could benefit from the introduction of ethical attributes for PLBs distributed through their higher reputation stores to a greater extent, or achieve a greater payoff by focusing the communication and promotion of ethical attributes offered through their PLBs on higher reputation stores.

\section{Limitations and Future Research}

Several limitations of the current research need to be acknowledged. First, experiment 1 paired a PLB with a NB and required participants to evaluate both brands. Although this design closely approximates a point-of-purchase decision context in which consumers view and compare multiple brands, it may have contributed to the observed lack of an ethical attribute effect on NB evaluations. Participants may have compared the NB to the PLB and may have found it superior to an extent that the ethical attribute did not add incremental benefits to the NB. 
Experiment 2 sought to address this concern in that it matched the NB and PLB in terms of consumer preference, and in examining whether an ethical attribute benefits a NB when the brand is evaluated in isolation (e.g., placed within end-of-aisle or promotional displays).

Experiment 2 also involved a different NB to investigate the robustness of NB results. In line with experiment 1 , a positive effect of ethical attribute presence did not arise for the NB.

Although this is not inconsistent with prior research that shows mixed effects of ethical attributes for NBs (Arora \& Henderson, 2007; Du et al., 2007), the effects of ethical attributes on NBs deserve further attention in future research. To examine whether the current research can shed more light on the contexts in which NBs may benefit from offering ethical attributes, we examined experiment 2 data in more detail. In this experiment, we had assessed to what degree consumers infer quality from price (price-quality beliefs; three items adapted from Netemeyer, Ridgway, \& Burton, 1993; e.g., "For [orange juice], the price is a reliable indication of product's quality.” $\alpha=.90)$. A regression analysis with price, brand, ethical attribute presence (EA), and price-quality (PQ) beliefs as predictors and brand attitude as the dependent variable, revealed no significant four-way interaction $(p>.60)$, but two significant three-way interactions, namely EA $\times$ price $\times$ brand $(B=-.21, t=-2.60, p=.01)$ and $\mathrm{EA} \times$ brand $\times$ PQ $(B=.11, t=1.97, p=.05)$. The former interaction is consistent with ANOVA results reported in experiment 2 (i.e., significant positive [negative] impact of EA on PLBs when price is high [low]). An examination of the latter interaction using the Johnson-Neyman technique indicated that for consumers with low price-quality beliefs $(\leq 2.1)$, the EA $\times$ brand interaction was negative and marginally significant, such that an ethical attribute had a more positive effect for the PLB (vs. NB). For consumers with high price-quality beliefs $(\geq 6.2)$, the EA $\times$ brand interaction was positive and marginally significant, suggesting that ethical attribute had a more positive effect for the NB (vs. 
PLB). This suggests that consumers who infer quality from price (high PQ belief) also use brand (i.e., NB) as a quality cue and tend to respond to ethical attribute offered by the NB more positively. Consumers who do not rely on price as an extrinsic cue (low PQ beliefs) may be generally more likely to assess quality based on product attributes rather than extrinsic cues; for these consumers, ethical attribute presence had a somewhat more positive effect on PLB evaluations. Although these results are preliminary, they suggest that consumer characteristics may moderate the effect of ethical attributes on NB evaluations.

Second, in order to control for differences in brand associations and credibility of the ethical attribute scenario arising from the use of different, pre-existing brands, we manipulated the price level, but not the brand name of the PLB in the experiments. This means that the same PLB (Our Finest) served as the high-priced as well as the low-priced PLB in this research. Although this increased experimental control—and may in fact have resulted in a more conservative test of the hypotheses because the PLB was not associated with extremely low evaluations in the pretest. An alternative way of approaching the hypothesis tests regarding differences between high-priced versus low-priced PLBs would have involved the use of actual low-price/low-quality PLBs (e.g., Walmart's Great Value or Price First), but differences in familiarity and prior associations with these brands could have created confounds.

In addition, although we sought to include a range of brands (i.e., NBs: Lay's, Oasis; PLBs: Our Finest, President's Choice), product categories (i.e., potato chips, orange juice, laundry detergents, hand soap), and ethical attributes (i.e., made from natural and locally grown or supplied ingredients; environmentally friendly) in the experiments reported herein, the findings of this research are nonetheless based on a limited range of stimuli. Importantly, the product brands represented in this research were grocery products that are associated with 
relatively low prices (under \$10) and limited price variability. To extend the current findings, it would be insightful to examine whether the pattern of results observed in the current research would arise in the context of higher-priced product categories (e.g., $\$ 100, \$ 1000, \$ 10,000$ etc.) or product-categories associated with higher price variability across brands (e.g., NB for $\$ 150$ and PLB for \$50). Consumers' information processing strategies are likely to differ in such contexts (e.g., involvement with the product and the choice task increases), and this could affect the weight given to the presence of ethical attributes.

In regard to the differential benefit arising from ethical attributes for PLBs versus NBs, it is important to acknowledge that attitudes toward private label brands are negatively related to risk aversion (Burton, Lichtenstein, Netemeyer, \& Garretson, 1998; Batra \& Sinha, 2000). Similarly, perceived risk negatively affects likelihood to adopt PLBs (Richardson, Jain, \& Dick, 1996). It is therefore possible that an ethical attribute is more beneficial for PLB than NB in product categories in which perceived risk is low rather than high, as was the case with the commonly purchased grocery products (e.g., chips, orange juice, laundry detergent, hand soap) represented in this research. Perceived risk associated with the product category may thus function as an important boundary condition for the ethical attribute effects observed in this research. An exploration of the effect of adding an ethical attribute in low risk (e.g., grocery products) versus high risk product categories (e.g., baby foods, over-the-counter medication) might therefore be a promising avenue for future research. The marketing literature has only recently begun to consider potential negative effects ethical attributes on consumers' evaluations of products and brands (Lin \& Chang, 2012; Luchs et al., 2010; Torelli et al., 2012). Further inquiries regarding moderators of the ethical attribute-brand evaluation relation could therefore contribute to current knowledge regarding ethical attribute effects on products and brands. 


\section{Footnotes}

1. A survey conducted between February 18 and March 8, 2013 polled more than 29,000 online consumers in 58 countries throughout Asia-Pacific, Europe, Latin America, the Middle East, Africa and North America.

2. When we included ethical attribute relevance as a covariate, there was a marginally significant main effect of ethical attribute relevance on brand appeal $(F>3.52, p=.063)$. However, the significance level and the effect size for the two-way interaction improved for brand appeal (from $F>4.53, p=.035$, partial $\eta^{2}=.031$ to $F>8.22, p=.005$, partial $\eta^{2}=.055$ ) and the pattern of the interaction did not change, ruling out differential relevance of ethical attribute to the brands as an alternative explanation. Similarly, when we included brand selfconnection as a covariate, there was a significant main effect of brand self-connection on brand appeal $(F>5.67, p=.019)$. However, the significance level and the effect size for the two-way interaction improved for brand appeal (from $F>4.53, p=.035$, partial $\eta^{2}=.031$ to $F$ $>5.70, p=.018$, partial $\left.\eta^{2}=.039\right)$ and the pattern of the interaction did not change. 


\section{References}

AMA (American Marketing Association) (2014). Retrieved from:

https:/www.ama.org/resources/Pages/Dictionary.aspx?dLetter=N

Arora, N., \& Henderson, T. (2007). Embedded premium promotion: Why it works and how to make it more effective. Marketing Science, 26(4), 514-531.

Auger, P., Devinney, T. M., Louviere, J. J., \& Burke, P. F. (2008). Do social product features have value to consumers? International Journal of Research in Marketing, 25(3), 183191.

Barone, M. J., Miyazaki, A. D., \& Taylor, K. A. (2000). The influence of cause-related marketing on consumer choice: Does one good turn deserve another? Journal of the Academy of Marketing Science, 28(2), 248-262.

Batra, R., \& Sinha, I. (2000). Consumer-level factors moderating the success of private label brands. Journal of Retailing, 76(2), 175-191.

Berens, G., Van Riel, C. B. M., \& Van Rekom, J. (2007). The CSR-quality trade-off: When can corporate social responsibility and corporate ability compensate each other? Journal of Business Ethics, 74(3), 233-252.

Bodur, H. O., Gao, T., \& Grohmann, B. (2014). The ethical attribute stigma: Understanding when ethical attributes improve consumer responses to product evaluations. Journal of Business Ethics, 122(1), 167-177. doi:10.1007/s10551-013-1764-5

Brown, T. J., \& Dacin, P. A. (1997). The company and the product: Corporate associations and consumer product responses. Journal of Marketing, 61(1), 68-84.

Burt, S. (2000). The strategic role of retail brands in British grocery retailing. European Journal of Marketing, 34(8), 875-890. 
Burton, S., Lichtenstein, D. R., Netemeyer, R. G., \& Garretson, J. A. (1998). A scale for measuring attitude toward private label products and an examination of its psychological and behavioral correlates. Journal of the Academy of Marketing Science, 26(4), 293-306.

Dawar, N., \& Parker, P. (1994). Marketing universals: Consumers' use of brand name, price, physical appearance, and retailer reputation as signals of product quality. Journal of Marketing, 58(1), 81-95.

Dodds, W. B., Monroe, K. B., \& Grewal, D. (1991). Effects of price, brand, and store information on buyers' product evaluations. Journal of Marketing Research, 28(3), 307319.

Du, S., Bhattacharya, C. B., \& Sen, S. (2007). Reaping relational rewards from corporate social responsibility: The role of competitive positioning. International Journal of Research in Marketing, 24 (3), 224-241.

Escalas, J. E., \& Bettman, J. R. (2003). You are what they eat: The influence of reference groups on consumers' connections to brands. Journal of Consumer Psychology, 13(3), 339-348.

Geyskens, I., Gielens, K., \& Gijsbrechts, E. (2010). Proliferating private-label portfolios: How introducing economy and premium private labels influences brand choice. Journal of Marketing Research, 47(5), 791-807.

Grewal, D., Krishnan, R., Baker, J., \& Borin, N. (1998). The effect of store name, brand name and price discounts on consumers' evaluations and purchase intentions. Journal of Retailing, 74(3), 331-352.

Grohmann, B., \& Bodur, O. (in press). Brand social responsibility: Conceptualization, measurement, and brand outcomes. Journal of Business Ethics. doi: 10.1007/s10551-0142279-4. 
Gupta, R., \& Sen, S. (2013). The effect of evolving resource synergy beliefs on the intentionsbehavior discrepancy in ethical consumption. Journal of Consumer Psychology, 23(1), $114-121$.

Hayes, A. F. (2013). Introduction to Mediation, Moderation, and Conditional Process Analysis: A Regression-based Approach. Guilford: New York, NY.

Henderson, T., \& Arora, N. (2010). Promoting brands across categories with a social cause: Implementing effective embedded premium programs. Journal of Marketing, 74(4), 4160.

Irwin, J. R., \& Naylor, R. W. (2009). Ethical decisions and response mode compatibility: Weighting of ethical attributes in consideration sets formed by excluding versus including product alternatives. Journal of Marketing Research, 46(2), 234-246.

Kardes, F. R., Cronley, M. L., Kellaris, J. J., \& Posavac, S. S. (2004). The role of selective information processing in price-quality inference. Journal of Consumer Research, 31(2), $368-374$.

Lichtenstein, D. R., Ridgway, N. M., \& Netemeyer, R. G. (1993). Price perceptions and consumer shopping behavior: A field study. Journal of Marketing Research, 30(2), 234245.

Lin, Y., \& Chang, C. A. (2012). Double standard: The role of environmental consciousness in green product usage. Journal of Marketing, 76(5), 125-134.

Luchs, M. G., Naylor, R. W., Irwin, J. R., \& Raghunathan, R. (2010). The sustainability liability: Potential negative effects of ethicality on product preference. Journal of Marketing, 74(5), 18-31. 
Luo, X., \& Bhattacharya, C. B. (2006). Corporate social responsibility, customer satisfaction, and market value. Journal of Marketing, 70(3), 1-18.

Milgrom, P., \& Roberts, J. (1986). Price and advertising as signals of product quality. Journal of Political Economy, 94, 796-821.

Monroe, K. B., \& Krishnan, R. (1985). The effect of price on subjective product evaluations. Perceived Quality, 1, 209-232.

Nielsen. (2008). Corporate ethics and fair trading: A Nielsen global consumer report. Retrieved from: http://pt.nielsen.com/documents/tr_200811_CSR_Fairtrade_global_reportOctober08.pdf

Nielsen. (2011). Private Brands U.S. Outlook: Flash in the Pan or the Real Deal? Retrieved from: http://nielsen.com/content/dam/corporate/campaigns/select-summit/Private-Label-USWhite-Paper-Dec-2011.pdf

Nielsen. (2012, March 27). The global, socially conscious consumers. Retrieved from http://www.nielsen.com/us/en/reports/2012/the-global--socially-consciousconsumer.html

Nielsen. (2013, October 8). Nielsen: $85 \%$ of global online respondents say rising food prices will impact their grocery choices. Retrieved from: http://www.nielsen.com/us/en/pressroom/2013/nielsen-85-of-global-online-respondents-say-rising-food-prices.html

Peloza, J., \& Shang, J. (2011). How can corporate social responsibility activities create value for stakeholders? A systematic review. Journal of the Academy of Marketing Science, 39(1), 117-135. 
Peloza, J., White, K., \& Shang, J. (2013). Good and guilt-free: The role of self-accountability in influencing preferences for products with ethical attributes. Journal of Marketing, 77(1), 104-119.

PLMA (Private Label Manufacturers Association) (2013). Retrieved from: http://www.plmainternational.com/industry-news/private-label-today

PLMA (Private Label Manufacturers Association) (2014). Retrieved from: http://plma.com/storeBrands/facts14a.html

Purohit, D., \& Srivastava, J. (2001). Effect of manufacturer reputation, retailer reputation, and product warranty on consumer judgments of product quality: A cue-diagnosticity framework. Journal of Consumer Psychology, 10(3), 123-134.

Rao, V. R., Agarwal, M. K., \& Dahlhoff, D. (2004). How is manifest branding strategy related to the intangible value of a corporation?. Journal of Marketing, 68(4), 126-141.

Rao, A. R., \& Monroe, K. B. (1988). The moderating effect of prior knowledge on cue utilization in product evaluations. Journal of Consumer Research, 15(2), 253-264.

Rao, A. R., \& Monroe, K. B. (1989). The effect of price, brand name, and store name on buyers' perceptions of product quality: An integrative review. Journal of Marketing Research, $26(3), 351-357$.

Richardson, P. S., Dick, A. S., \& Jain, A. K. (1994). Extrinsic and intrinsic cue effects on perceptions of store brand quality. Journal of Marketing, 58(4), 28-36.

Richardson, P. S., Jain, A. K., \& Dick, A. (1996). Household store brand proneness: a framework. Journal of Retailing, 72(2), 159-185.

Sethuraman, R. (2003). Measuring National Brands' Equity over Store Brands. Review of Marketing Science, 1(2), 1-29. 
Shiv, B., Carmon, Z., \& Ariely, D. (2005). Placebo effects of marketing actions: Consumers may get what they pay for. Journal of Marketing Research, 42(4), 383-393.

Steenkamp, J-B. E. M., Van Heerde, H. J., \& Geyskens, I. (2010). What makes consumers willing to pay a price premium for national brands over private labels? Journal of Marketing Research, 47 (4), 1011-1024.

Steiner, R. L. (2004). The nature and benefits of national brand/private label competition. Review of Industrial Organization, 24(2), 105-127.

Tellis, G.J., \& Zufryden, F.S. (1995). Tackling the retailer decision maze: Which brands to discount, how much, when, and why? Marketing Science, 14(3), 271-99.

Torelli, C. J., Monga, A. B., \& Kaikati, A. M. (2012). Doing poorly by doing good: Corporate social responsibility and brand concepts. Journal of Consumer Research, 38(5), 948-963.

Trudel, R., \& Cotte, J. (2009). Does it pay to be good? Sloan Management Review, 50, 61-68.

Van Osselaer, S. M., \& Alba, J. W. (2003). Locus of equity and brand extension. Journal of Consumer Research, 29(4), 539-550.

Varadarajan, P. R., \& Menon, A. (1988). Cause-related marketing: A coalignment of marketing strategy and corporate philanthropy. Journal of Marketing, 52(3), 58-74.

Volpe, R. (2011). The relationship between national brand and private label food products prices, promotions, recessions, and recoveries. USDA Economic Research Report, 129, 1-25. 
Figure 1. The Effect of Ethical Attributes on PLB Evaluation is Positive When Price is High But Negative When Price is Low (Experiment 1)

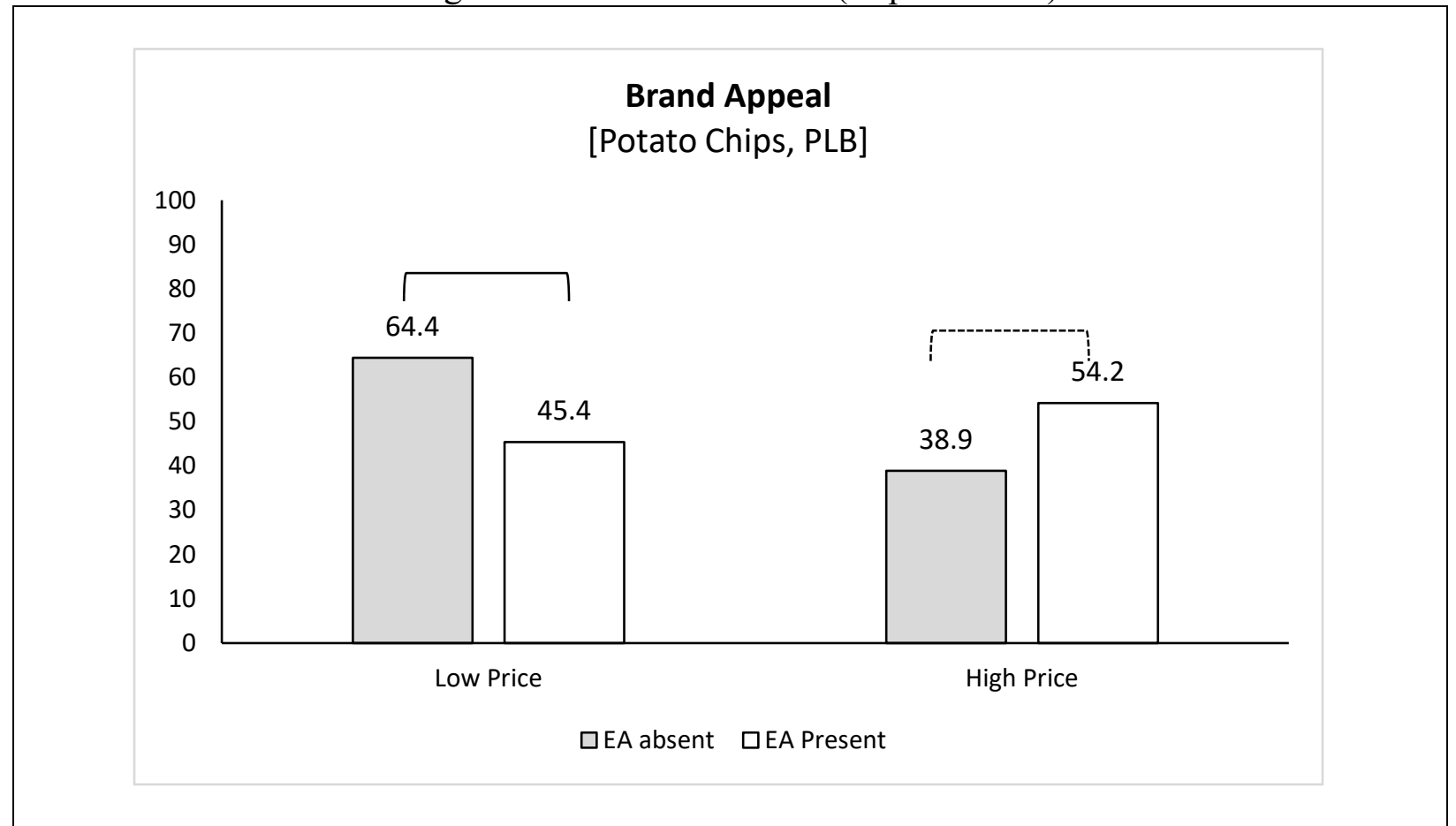

Note: Solid brackets indicate significant differences at $\mathrm{p}<.05$ and dashed brackets at $\mathrm{p}<.10$. 
Figure 2. Impact of Price, Ethical Attribute (EA), and Brand on Evaluations (Experiment 2)

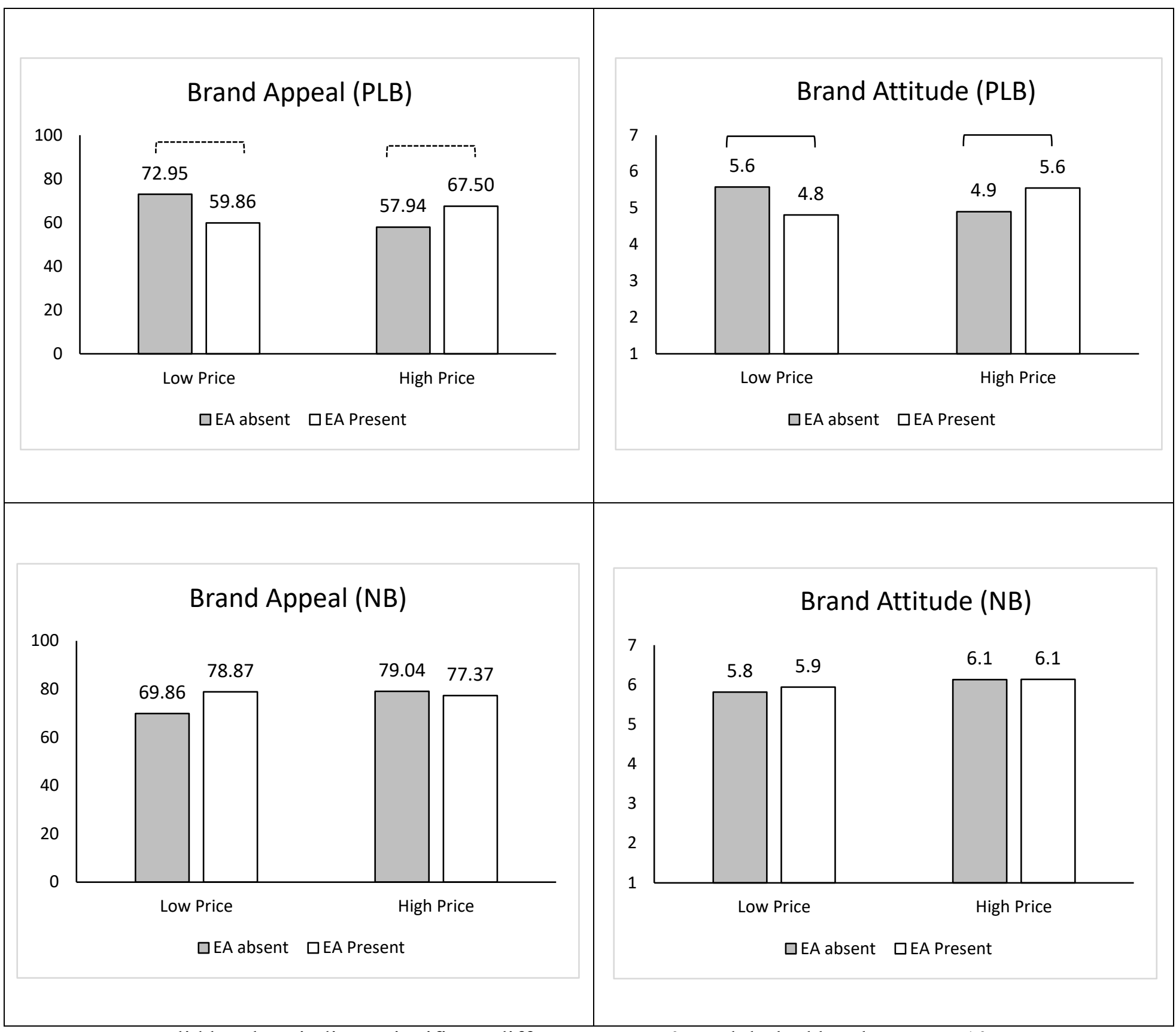

Note: Solid brackets indicate significant differences at $\mathrm{p}<.05$ and dashed brackets at $\mathrm{p}<.10$. 
Figure 3. PLB Evaluations Increase for Ethical Attribute Presence at High Retailer Reputation (Experiment 3)

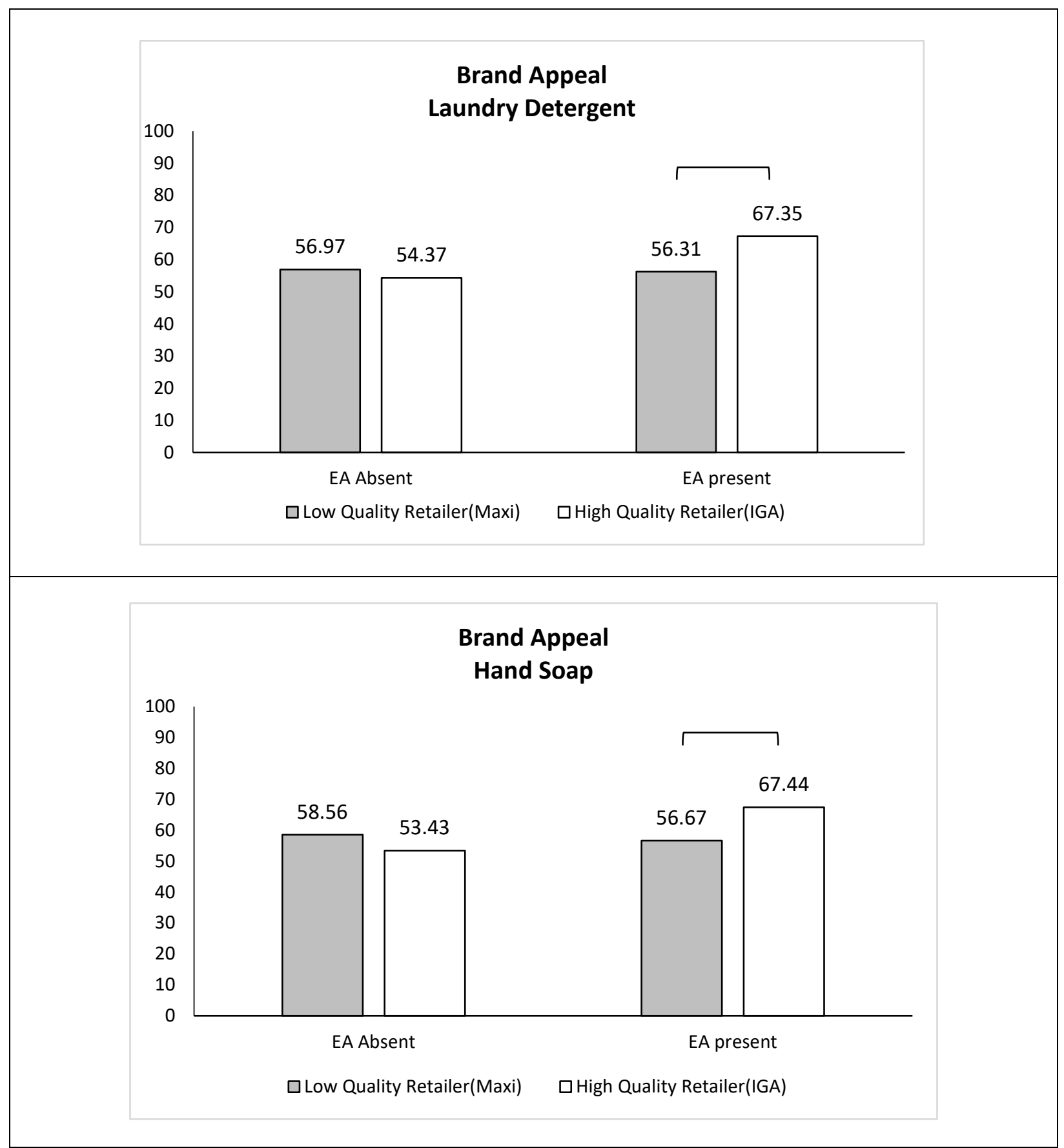

Note: Solid brackets indicate significant differences at $p<.05$. 
Figure 4. Effect of Retailer Reputation, Ethical Attribute (EA), and Resource Synergy Beliefs on PLB Evaluations (Experiment 3)

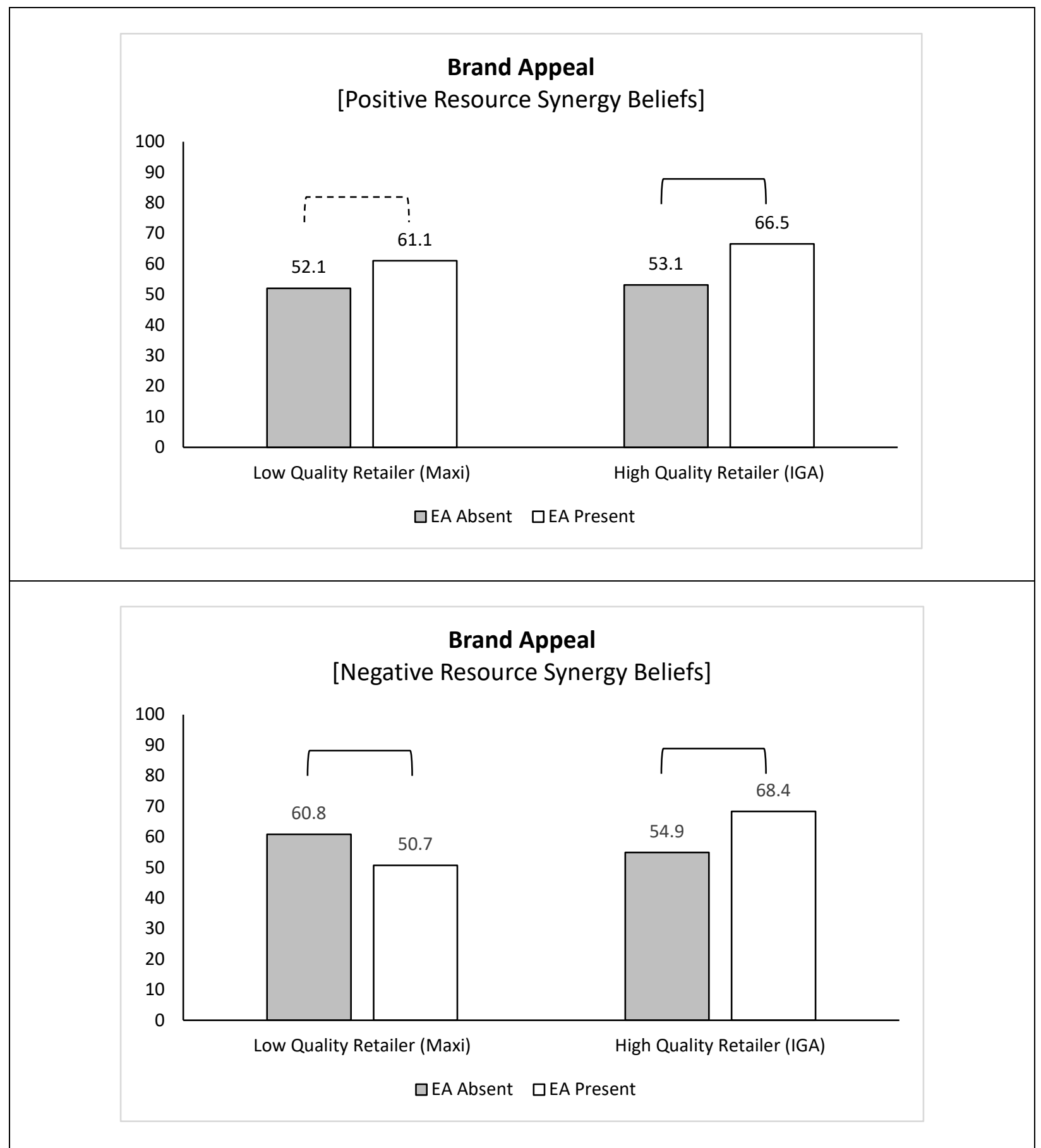

Notes: Solid brackets indicate significant differences at $\mathrm{p}<.05$ and dashed brackets at $\mathrm{p}<.10$. 


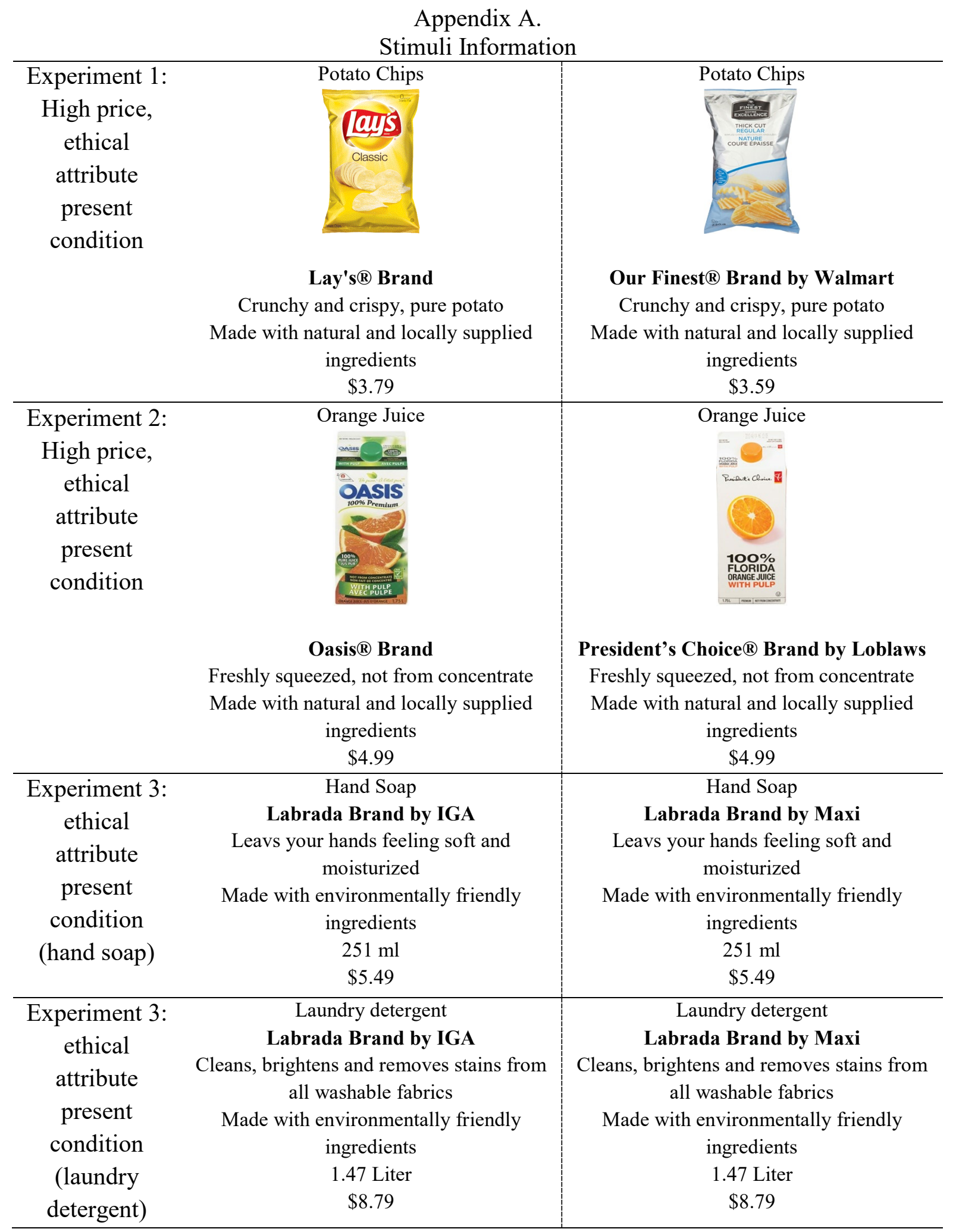

